\title{
Endobronchial valve positioning for alveolar-pleural fistula following ICU management complicating COVID-19 pneumonia
}

\author{
Pierluigi Donatelli ${ }^{1 \dagger}$, Fabiana Trentacosti ${ }^{1 \dagger}$, Maria Rosaria Pellegrino ${ }^{1}$, Roberto Tonelli, ${ }^{1,2,5,6^{*}} \mathbb{0}$, Giulia Bruzzi $^{1}$, \\ Alessandro Andreani ${ }^{1}$, Gaia Francesca Cappiello ${ }^{1}$, Dario Andrisani 1,2, Filippo Gozzi 1,2, Cristina Mussini ${ }^{3}$, \\ Stefano Busani ${ }^{4}$, Gilda Valentina Cavaliere ${ }^{4}$, Massimo Girardis ${ }^{4}$, Elisabetta Bertellini ${ }^{4}$, Enrico Clini ${ }^{1}$ and \\ Alessandro Marchioni ${ }^{1}$
}

\begin{abstract}
Background: The main clinical consequences of severe acute respiratory syndrome Coronavirus 2 (SARS-CoV-2) infection are pneumonia and respiratory failure even requiring mechanical ventilation. In this context, the lung parenchyma is highly prone to ventilator-related injury, with pneumothorax and persistent air leak as the most serious adverse events. So far, endobronchial valve (EBV) positioning has proved efficacious in treating air leaks with a high success rate.

Case presentation: We report, for the first time, two cases of patients affected by SARS-CoV-2-related pneumonia complicated with bacterial super-infection, experiencing pneumothorax and persistent air leaks after invasive mechanical ventilation. Despite the severity of respiratory failure both patients underwent rigid interventional bronchoscopy and were successfully treated through EBV positioning.

Conclusions: Persistent air leaks may result from lung tissue damage due to a complex interaction between inflammation and ventilator-related injury (VILI), especially in the advanced stages of ARDS. EBV positioning seems to be a feasible and effective minimally invasive therapeutic option for treating this subset of patients.
\end{abstract}

Keywords: COVID-19, Alveolar-pleural fistula, Endobronchial valve, Pneumothorax, Klebsiella pneumoniae

\section{Background}

A case clusters of pneumonia caused by the novel severe acute respiratory syndrome coronavirus 2 (SARS-CoV-2) was first reported in Wuhan city of China in December 2019, then spread worldwide [1]. Clinical presentations of coronavirus related disease (COVID-19) vary

\footnotetext{
*Correspondence: roberto.tonelli@me.com

${ }^{\dagger}$ Pierluigi Donatelli and Fabiana Trentacosti share first authorship

${ }^{2}$ Clinical and Experimental Medicine PhD Program, University of Modena

Reggio Emilia, Via Università 4, 41121 Modena, Italy

Full list of author information is available at the end of the article
}

from asymptomatic to mild influenza-like symptoms to life-threatening pneumonia, whilst multiorgan failure can also occur [1,2]. COVID-19 acute lung injury results from exaggerated inflammation started by viral replication and then sustained by a cytokine storm that is associated with disease severity [3, 4]. Although the physiopathological features of respiratory failure caused by SARS-CoV-2 infection may be heterogeneous, in most severe cases of COVID-19, acute respiratory distress syndrome (ARDS) occurs [5]. In these patients, high elastance and severe lung inhomogeneity make the 
parenchyma prone to ventilator-induced lung injury (VILI) when mechanical ventilation (MV) is applied [6, 7]. Positive pressure ventilation, especially at the interface between structures with different extensibilities, may lead to harmful transpulmonary pressure causing the rupture of extracellular polymers, resulting in "barotrauma", of which the most common form is pneumotho$\operatorname{rax}[9,10]$. Despite the onset of pneumothorax requiring chest drainage having been reported in 5.9\% of COVID19 patients undergoing MV [11], only a few cases of persistent air leak (PAL) have been described to date. PAL is defined as an air leak that persists for more than 5-7 days [12]. A bronchopleural fistula (BPF) occurs when PALs are supported by a communication between the bronchus and the pleural space, whereas an alveolar-pleural fistula (APF) follows a distal origin of PALs [12, 13]. PALs are known to be the one of common complications after lung surgery [14]; however, APF is not frequently associated with an excessive stress/strain applied to the lung parenchyma by MV. Nonetheless, this clinical condition has serious consequences for patient management and outcome resulting in prolonged chest tube maintenance and hospital stay, and in a higher rate of infectious complications due to loss of sterility in the pleural space [12, 13]. Retrospective studies in patients with PALs have shown mortality rates ranging from 16 to $72 \%$ [11]. Treatment options include conservative management, surgical repair, and minimally invasive interventional pulmonology or bronchoscopic management $[13,15]$.

We present two cases of severe COVID-19 pneumonia complicated by bacterial pneumonia and APF secondary to VILI and treated through EBV positioning.

\section{Case presentation}

Case 1

In March 2020, a 67-year-old Caucasian male was admitted to the respiratory ward at the Hospital of Piacenza (Italy) presenting with fever $\left(38{ }^{\circ} \mathrm{C}\right)$ and respiratory failure. His past medical history was characterized by well controlled asthma and hypertension. SARS-CoV-2 infection was confirmed by real time polymerase chain reaction (RT-PCR) assay on nasopharyngeal and throat specimens. Blood tests showed increased D-Dimer $(657 \mathrm{ng} / \mathrm{mL})$, elevated C reactive protein (CRP) $(20.3 \mathrm{mg} /$ $\mathrm{dL}$ ) and procalcitonin (PCT) (0.9 ng/L). Oxygen supply was started in addition to hydroxychloroquine, azithromycin, darunavir-cobicistat, and ceftazidime. Given the rapid worsening of respiratory failure, the patient was transferred to the University Hospital of Modena where continuous positive airway pressure through a helmet was started, and Tocilizumab was infused. Following further deterioration, the patient underwent endotracheal intubation and was then transferred to the Intensive Care
Unit (ICU) where invasive MV in volume-controlled mode with protective strategy was initiated. Successful extubation occurred 8 days later, thus cycles of intermittent high flow nasal cannula (HFNC) and non-invasive ventilation (NIV) were set. Due to septic shock of presumable pulmonary origin associated with chest X-ray worsening and Klebsiella pneumoniae bacteremia, the patient again underwent endotracheal intubation 14 days later. After 5 days, the MV regimen was complicated by the onset of right tension hydro-pneumothorax requiring decompression and insertion of chest drainage. Chest computed tomography confirmed the occurrence of a large right pneumothorax with associated pleural effusion (Fig. 1, Panel A). Klebsiella pneumoniae and Enterococcus faecalis were isolated from bronchoalveolar lavage, thus antibiotic therapy with meropenem and ampicillin was started. After 8 days, the patient was successfully weaned from MV, although the pneumothorax had not resolved with significant PAL over 3 weeks. Since an APF was assumed to be the cause, the patient was transferred to the Respiratory Unit, flexible bronchoscopy was performed, and the middle lobe was identified as the source of the air leak using a balloon occlusion test. Two valves (EBVs Zephir, size $5 \mathrm{~mm}$; Zephyr ${ }^{\circledR}$ Endobronchial Valve System Pulmonx Corporation, Redwood City, CA 94063 USA) were successfully inserted into the segmentary bronchi of the middle lobe (Fig. 1, Panel B) resulting in reduction in air leak after 3 days. No residual air leak was detected in the following week, so that, once cleansing of pleural fluid was observed, drainage tube was removed successfully, as further confirmed by the chest X-ray check. In June the patient was transferred to the Hospital of Piacenza given the clinical stability, and was then discharged a month later, after pulmonary rehabilitation. A chest CT scan was performed two months later showing improvement of pneumothorax, thus suggesting APF reduction. Valves were removed 8 months later and follow-up was started. To date no recurrence of pneumothorax was reported.

\section{Case 2}

In March 2020, a 73-year-old Caucasian male was admitted to the Infectious Diseases Unit of the University Hospital of Modena (Italy) with persistent fever $\left(38.8{ }^{\circ} \mathrm{C}\right)$ and severe acute hypoxic respiratory failure $\left(\mathrm{PaO}_{2} /\right.$ $\mathrm{FiO}_{2}=150 \mathrm{mmHg}$ ). A nasopharyngeal swab (RT-PCR) tested positive for SARS-CoV-2. Chest X-ray showed bilateral interstitial infiltrates while blood tests reported increased CRP $(20.8 \mathrm{mg} / \mathrm{dL})$ and PCT $(2.8 \mathrm{ng} / \mathrm{mL})$. Oxygen supply was started along with hydroxychloroquine, azithromycin, and ceftriaxone. On the following day, the patient presented a significant worsening of gas exchange, thus continuous positive airway pressure through a 

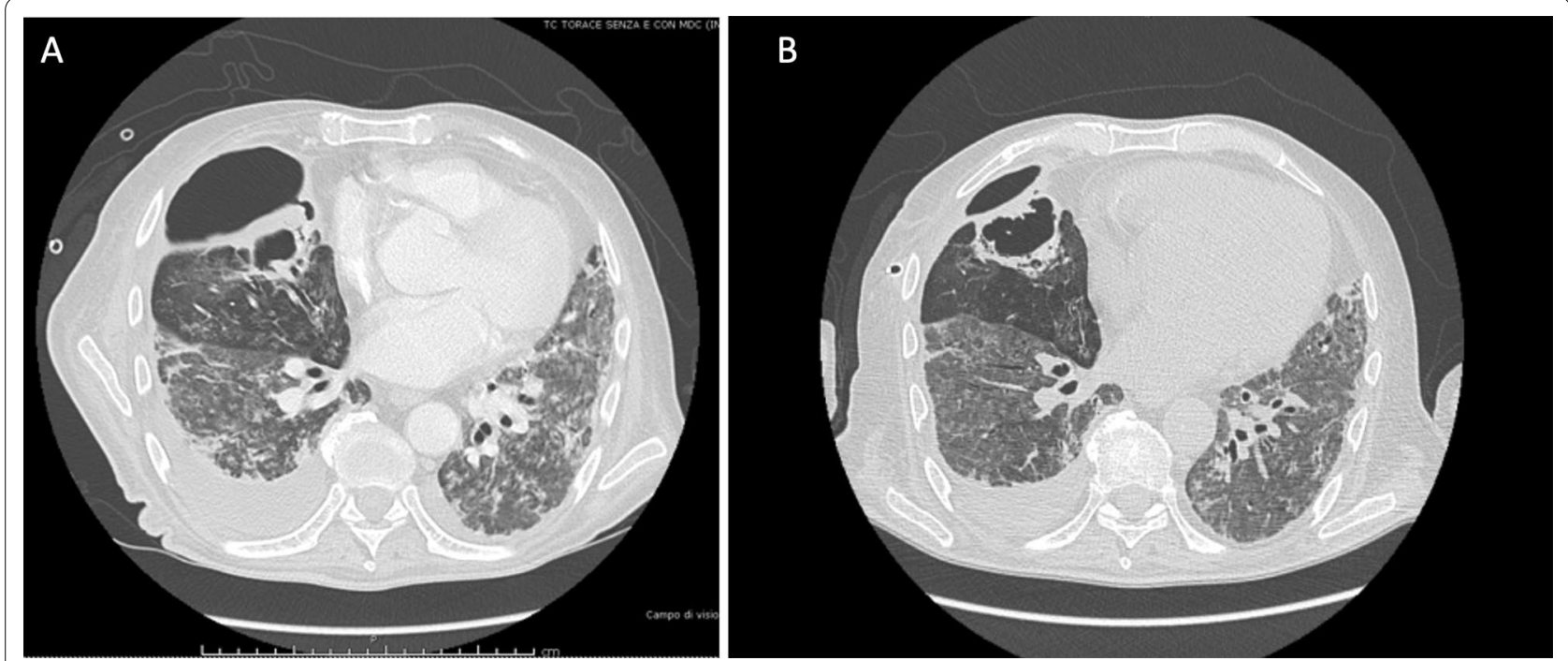

Fig. 1 High resolution computed tomography scan in Case 1 showing right pneumothorax secondary to alveolar-pleural fistula (APF) before (panel A) and after (panel B) endobronchial valve (EBV) positioning with lung parenchyma re-expansion

helmet was started and Tocilizumab was infused. In spite of this and because of further worsening of his condition, the patient was admitted to the ICU where invasive volume-preset MV was initiated with protective strategy. A tracheostomy was performed on day 10 after ICU admission. On day 15, the occurrence of right hydro-pneumothorax (Fig. 2, panel A) required immediate insertion of a chest drainage tube. Klebsiella pneumoniae and Enterococcus faecalis were isolated from pleural fluid and successfully treated with meropenem and ampicillin. After 1 month, his clinical condition had improved markedly and weaning from MV was achieved, despite the persistence of right pneumothorax and air leak due to suspected APF. Thus, the patient was transferred to the respiratory ICU where flexible bronchoscopy was performed, and a balloon occlusion test identified the presence of APF in the right lower lobe. Three valves (EBVs Zephir, size $5 \mathrm{~mm}$ ) were inserted into the segmental
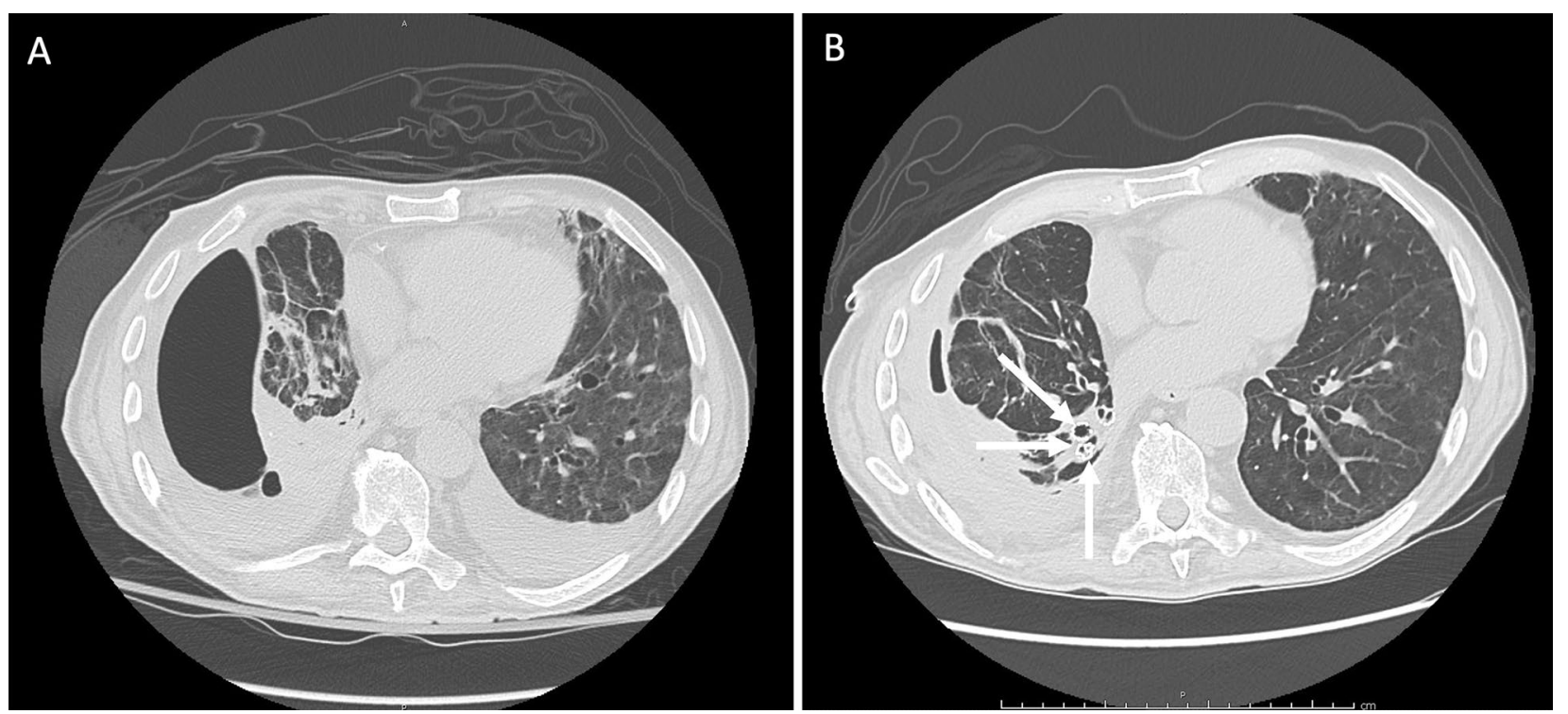

Fig. 2 High resolution computed tomography scan in Case 2 showing right pneumothorax secondary to alveolar-pleural fistula (APF) before (panel A) and after (panel B) endobronchial valve (EBV) positioning with lung parenchyma re-expansion. Valves can be observed in the basal pyramid bronchi (withe arrows) 
bronchi of the right lower lobe (Fig. 2, panel B). A gradual reduction of air leak was recorded over the following week, although resolution was only obtained after the further placement of a valve in the apical segment of the right lower lobar bronchus. Finally, the drainage tube was removed, and the patient was discharged on July 2020. In October 2020 he underwent endoscopic removal of endobronchial valves without any complication.

\section{Discussion and conclusion}

COVID-19 exhibits a broad spectrum of clinical conditions, including pneumonia, ARDS, pulmonary embolism, and hearth failure, leading to the development of respiratory failure often requiring ICU management and MV (in about 20\% of cases) [16]. The pathogenesis of respiratory failure is complex and covers different clinical scenarios ranging from patients with relatively spared lung compliance to patients with ARDS mechanical features. [5, 17]. Most patients admitted to the ICU with severe COVID-19 pneumonia fulfill ARDS criteria and require $M V$, which in turn may lead to a VILI [18]. The high stress level generated during MV associated with lung tissue inflammation can cause bronchial or alveolar ruptures followed by pneumothorax or pneumomediastinum. Gammon et al. have shown that ARDS per se is an independent risk factor, although the less aggressive use of pressure, in the lung protective strategy era, was associated with a markedly lower incidence of pneumothorax [8]. Both cases underwent MV with protective strategy (expiratory tidal volume [Vte] $<6 \mathrm{ml} / \mathrm{kg}$ of predicted body weight, plateau pressure $\left[\mathrm{P}_{\text {plat }}\right]<28 \mathrm{cmH}_{2} \mathrm{O}$, PEEP titration according to $\mathrm{FiO}_{2}$ schedule) and were not subjected to recruitment maneuvers. In this scenario, it may be speculated that regional factors associated to lung inhomogeneity due to advanced stages of COVID-19 related ARDS and inflammatory related tissue frailty, could have played a major role in exacerbating barotrauma, resulting in APF. In the previous SARS outbreak, barotrauma was a common complication during MV. Indeed, studies in mechanically ventilated SARS patients showed a high incidence of pneumothorax (20-30\%) and pneumomediastinum (12\%) [19-22]. Patients with a lower $\mathrm{PaO}_{2} / \mathrm{FiO}_{2}$ ratio, higher $\mathrm{PaCO}_{2}$, and higher respiratory rate during ICU stay were at a greater risk of developing pneumothorax [23]. The incidence of SARS-CoV-2-related pneumothorax appears to be significantly lower $(5.9 \%)$ than reported in patients with SARS-CoV-1, but it can lead to a mortality of $30 \%$ [24]. Moreover, studies performed in non-SARS-CoV-2 patients with ARDS showed that overinflation and distortion of lung structures due to MV could result in emphysema-like lesions, lung cysts, and bronchiectasis [25]. In the late stages of ARDS, these lesions prevail in nondependent and caudal lung regions as confirmed by chest CT scan [26]. Furthermore, experimental studies in animals have demonstrated that MV set at high tidal volume or high PEEP and recruitment maneuvers results in air space enlargement after 2 days $[27,28]$.

Radiologic studies in COVID-19 with ARDS have shown that patients can develop cystic lung parenchyma changes and bullae formation during viral infection [29]. These parenchymal changes may predispose patients undergoing MV to develop pneumothorax and PALs, especially in the advanced stage when the lung has possibly undergone fibrotic changes. Since the fibrotic lung is particularly subject to static strain, the hyperinflation achieved with the addition of PEEP can facilitate enlargement of the air spaces in non-dependent areas of the lung [30]. Moreover, both cases showed the isolation of Klebsiella pneumoniae and Enterococcus faecalis from bronchoalveolar lavage (Case 1) and pleural fluid (Case 2). A bacterial super-infection may have enhanced the inflammatory mechanism of lung injury already triggered by SARS-CoV-2 infection, thus increasing the susceptibility to PALs development. Indeed, necrotizing infections of the lung caused by gram negative bacteria (namely Klebsiella pneumoniae) have been widely reported [31]. Given the lack of evident signs of fistulisation at bronchoscopic examination we concluded for APF diagnosis for both cases.

Traditional approaches to PALs range from watchful waiting with prolonged chest tube placement to more invasive measures including surgery. There is a recent report of two COVID-19 patients with PALs successfully treated with thoracoscopy, blebs resection, and pleurectomy [32]. Different less invasive options have been tested, such as autologous blood pleurodesis, Heimlich valve positioning, and albumin-glutaraldehyde tissue adhesives [13]. Recently a BPF related PAL was successfully treated with EBV placement [33]. To our knowledge, these are the first two cases documenting the effective use of EBVs to treat PALs due o APF in patients infected with novel SARS-CoV-2 who required invasive MV.

EBV was first administered for lung volume reduction in patients with severe emphysema [34], and it is currently the most actively performed procedure for PALs, when surgical options are not viable [13, 15]. EBV has been approved by the Food and Drug Administration to treat PALs under humanitarian use regulations, reducing airflow across the fistula and allowing healing and resolution [35]. In a multicenter study with 40 patients, Travaline et al. showed that Zephyr EBV is an effective minimally invasive device for completely treating PALs in around half of the treated patients, and complications such as valve malposition and/or expectoration, and pneumonia are quite rare [36]. 
Localization of PALs is challenging, and the balloon occlusion method is currently the most used approach [13]. Our two patients experienced continuous bubbling during inspiration/expiration, i.e. grade 4 according to the Cerfolio classification of air leaks [13]. After the EBV procedure, both cases showed complete resolution of PALs from APF without any need for surgery.

Although, our reported experience in COVID-19 patients with iatrogenic PALs refractory to conservative strategy has demonstrated that the EBV procedure is feasible, safe, and effective, some limitations should be highlighted. First in severely hypoxic patients the bronchoscopic interventional procedure may worsen respiratory failure. Secondly, in patients with bacterial super-infection valve positioning may facilitate postobstructive pneumonia. Third, considering the risk of pneumothorax relapse, the timing of EBV removal should be carefully planned as data about the optimal management of these patients once air leaks resolution is achieved are lacking. However, in the most severe cases with an advanced stage of ARDS, at higher risk for iatrogenic PALs, the EBV procedure is likely to offer a reasonable minimally invasive therapeutic option.

\section{Abbreviations}

PEEP: Positive end-expiratory pressure; EBV: Endobronchial valve; VILI: Ventilator-induced lung injury; MV: Mechanical ventilation; HFNC: High flow nasal cannula; NIV: Non-invasive ventilation; PAL: Persistent air leak; APF: Alveolarpleural fistula; BPF: Bronco pleural fistula; RT-PCT: Real time polymerase chain reaction; SARS-CoV-2: Severe acute respiratory syndrome-coronavirus; COVID19: Coronavirus disease 19; ARDS: Acute respiratory distress syndrome; CRP: C reactive protein; CT: Computed tomography; ICU: Intensive Care Unit.

\section{Acknowledgements}

We would like to thank Editor Colin Woodham (Alpha Science Editors) for language editing.

\section{Authors' contributions}

F.T. and P.D. made substantial and equal contributions in the conception, writing and editing of the manuscript thus they should both be considered as first authors. M.R.P., G.B., A.A., G.F.C., D.A., and F.G. reviewed the literature and wrote the report. C.M., S.B., G.V.C., and E.B. reviewed the literature and contribute to discussion. R.T. and M.G. provided images and edited the manuscript. E.C. and A.M. reviewed and edited the manuscript. All authors read and approved the final manuscript.

\section{Funding}

None.

\section{Availability of data and materials}

The datasets used and/or analyzed during the current study are available from the corresponding author on reasonable request.

\section{Declarations}

\section{Ethics approval and consent to participate}

All procedures performed in studies involving human participants were in accordance with the ethical standards of the institutional and/or national research committee and with the 1964 Helsinki Declaration and its later amendments or comparable ethical standards.

\section{Consent for publication}

Written informed consent regarding publication was obtained from both patients included in the study.

\section{Competing interests}

The authors declare that they have no competing interests.

\section{Author details}

${ }^{1}$ University Hospital of Modena, Respiratory Diseases Unit, Department of Medical and Surgical Sciences, University of Modena Reggio Emilia, Modena, Italy. ${ }^{2}$ Clinical and Experimental Medicine PhD Program, University of Modena Reggio Emilia, Via Università 4, 41121 Modena, Italy. ${ }^{3}$ University Hospital of Modena, Infectious Diseases Unit, University of Modena Reggio Emilia, Modena, Italy. ${ }^{4}$ University Hospital of Modena, Anesthesiology Unit, University of Modena Reggio Emilia, Modena, Italy. ${ }^{5}$ Laboratory of Experimental Pneumology, Modena, Italy. ${ }^{6}$ Respiratory Diseases Unit and Center for Rare Lung Disease, Department of Surgical and Medical Sciences, University Hospital of Modena, Via del Pozzo, 71, 41125 Modena, Italy.

Received: 24 November 2020 Accepted: 1 September 2021

Published online: 27 September 2021

\section{References}

1. Huang C, Wang Y, Li X, Ren L, Zhao J, Hu Y, et al. Clinical features of patients infected with 2019 novel coronavirus in Wuhan, China. Lancet. 2020;395(10223):497-506. https://doi.org/10.1016/S0140-6736(20) 30183-5.

2. Zhou F, Yu T, Du R, Fan G, Liu Y, Liu Z, et al. Clinical course and risk factors for mortality of adult inpatients with COVID-19 in Wuhan, China: a retrospective cohort study. Lancet. 2020;395(10229):1054-62. https://doi.org/ 10.1016/S0140-6736(20)30566-3.

3. Ye Q, Wang B, Mao J. The pathogenesis and treatment of the 'Cytokine Storm' in COVID-19. J Infect. 2020;80(6):607-13. https://doi.org/10.1016/j. jinf.2020.03.037.

4. Fu Y, Cheng Y, Wu Y. Understanding SARS-CoV-2-mediated inflammatory responses: from mechanisms to potential therapeutic tools. Virol Sin. 2020;35(3):266-71. https://doi.org/10.1007/s12250-020-00207-4.

5. Gattinoni L, Chiumello D, Caironi P, Busana M, Romitti F, Brazzi L, et al. COVID-19 pneumonia: different respiratory treatments for different phenotypes? Intensive Care Med. 2020;46:1099-102. https://doi.org/10.1007/ s00134-020-06033-2.

6. Gattinoni L, Tonetti T, Quintel M. Regional physiology of ARDS. Crit Care. 2017;21(Suppl 3):312.

7. Cressoni M, Chiurazzi C, Gotti M, Amini M, Brioni M, Algieri I, et al. Lung inhomogeneities and time course of ventilator-induced mechanical injuries. Anesthesiology. 2015;123:618-27.

8. Gammon RB, Shin MS, Groves RH Jr, Hardin JM, Hsu C, Buchalter SE. Clinical risk factors for pulmonary barotraumas: a multivariate analysis. Am J Respir Crit Care Med. 1995:152:1235-40.

9. Karnik AA, Karnik AM. Pneumothorax and Barotrauma. Crit Care Med. 2008. https://doi.org/10.1016/B978-032304841-5.50050-9.

10. Boussarsar M, Thierry G, Jaber S, Roudot-Thoraval F, Lemaire F, Brochard L. Relationship between ventilatory settings and barotraumas in the acute respiratory distress syndrome. Intensive Care Med. 2002;28:406-13.

11. Yao W, Wang T, Jiang B, Gao F, Wang L, Zheng H, et al. Emergency tracheal intubation in 202 patients with COVID-19 in Wuhan, China: lessons learnt and international expert recommendations. Br J Anaesth. 2020;125(1):e28-37. https://doi.org/10.1016/j.bja.2020.03.026.

12. Sakata KK, Reisenauer JS, Kern RM, Mullon JJ. Persistent air leak - review. Respir Med. 2018;137:213-8. https://doi.org/10.1016/j.rmed.2018.03.017.

13. Dugan KC, Laxmanan B, Murgu S, Hogarth DK. Management of persistent air leaks. Chest. 2017;152(2):417-23. https://doi.org/10.1016/j.chest.2017. 02.020 (Epub 2017 Mar 4).

14. Zhao K, Mei J, Xia C, et al. Prolonged air leak after video-assisted thoracic surgery lung cancer resection: risk factors and its effect on postoperative clinical recovery. J Thorac Dis. 2017;9(5):1219-25. https://doi.org/10. 21037/jtd.2017.04.31. 
15. Bertolaccini L, Bonfanti B, Kawamukai K, Parri SNF, Lacava N, Solli P. Bronchoscopic management of prolonged air leak. J Thorac Dis. 2018;10(Suppl 27):S3352-5. https://doi.org/10.21037/jtd.2018.04.167.

16. Gattinoni L, Chiumello D, Rossi S. COVID-19 pneumonia: ARDS or not? Crit Care. 2020;24:154. https://doi.org/10.1186/s13054-020-02880-z.

17. Mehta P, McAuley DF, Brown M, Sanchez E, Tattersall RS, Manson JJ, et al. COVID-19: consider cytokine storm syndromes and immunosuppression. Lancet. 2020;395(10229):1033-4. https://doi.org/10.1016/S0140-6736(20) 30628-0.

18. Slutsky AS, Ranieri VM. Ventilator-induced lung injury. N Engl J Med. 2013;369:2126-36. https://doi.org/10.1056/NEJMra1208707.

19. Ruggeri P, Girbino G. Fatal pneumomediastinum associated with use of noninvasive mechanical ventilation. Respirol Case Rep. 2014;2(4):126-8. https://doi.org/10.1002/rcr2.73.

20. Lew TWK, Kwek TK, Tai D, Earnest A, Loo S, Singh S, et al. Acute respiratory distress syndrome in critically ill patients with severe acute respiratory syndrome. JAMA. 2003;290:374.

21. Fowler RA, Lapinsky SE, Hallett D, Detsky AS, Sibbald WJ, Slutsky AS, et al. Critically ill patients with severe acute respiratory syndrome. JAMA. 2003:290:373.

22. Peiris JSM, Chu CM, Cheng VCC, Chan KS, Hung IFN, Poon LLM, et al. Clinical progression and viral load in a community outbreak of coronavirus associated SARS pneumonia: a prospective study. Lancet. 2003;361:1767.

23. Kao HK, Wang JH, Sung CS, Huang YC, Lien TC. Pneumothorax and mortality in the mechanically ventilated SARS patients: a prospective clinical study. Crit Care. 2005;9:R440-5.

24. Quincho-Lopez A, Quincho-Lopez DL, Hurtado-Medina FD. Case report: pneumothorax and pneumomediastinum as uncommon complications of COVID-19 pneumonia-Literature review. Am J Trop Med Hyg. 2020;103(3):1170-6.

25. Rouby JJ, Lherm T, Martin de Lassale E, Poète P, Bodin L, Finet JF, et al. Histologic aspect of pulmonary barotrauma in critically ill patients with acute respiratory failure. Intensive Care Med. 1993;19:383.

26. Treggiari MM, Romand JA, Martin JB, Suter PM. Air cysts and bronchiectasis prevail in nondependent areas in severe acute respiratory distress syndrome: a computed tomographic study of ventilator-associated changes. Crit Care Med. 2020;30:1747-52.

27. Goldstein I, Bughalo MT, Marquette $\mathrm{CH}$, Lenaour G, Lu Q, Rouby JJ. Experimental ICU Study Group. Mechanical ventilation-induced air-space enlargement during experimental pneumonia in piglets. Am J Respir Crit Care Med. 2001;163:958-64.

28. Lim CM, Lee SS, Lee JS, Koh Y, Shim TS, Lee SD, et al. Morphometric effects of the recruitment maneuver on saline-lavaged canine lungs: a computed tomographic analysis. Anesthesiology. 2003;99:71-80.

29. Shi H, Han X, Jiang N, Cao Y, Alwalid O, Gu J, et al. Radiological findings from 81 patients with COVID-19 pneumonia in Wuhan, China. A descriptive study. Lancet Infect Dis. 2020;20:425.

30. Marchioni A, Tonelli R, Rossi G, Spagnolo P, Luppi F, Cerri S, et al. Ventilatory support and mechanical properties of the fibrotic lung acting as a "squishy ball." Ann Intensive Care. 2020;10:13.

31. Gadkowski LB, Stout JE. Cavitary pulmonary disease. Clin Microbiol Rev. 2008;21(2):305-33, table of contents. https://doi.org/10.1128/CMR.0006007. PMID: 18400799; PMCID: PMC2292573.

32. Aiolfi A, Biraghi T, Montisci A, Bonitta G, Micheletto G, Donatelli F, et al. Management of persistent pneumothorax with thoracoscopy and bleb resection in COVID-19 patients. Ann Thorac Surg. 2020;110:e413-5.

33. Talon A, Arif MZ, Mohamed H, Khokar A, Saeed Al. Bronchopleural fistula as a complication in a COVID-19 patient managed with endobronchial valves. J Investig Med High Impact Case Rep. 2021;9:23247096211013216.

34. Klooster K, ten Hacken NH, Hartman JE, Kerstjens HA, van Rikxoort EM, Slebos DJ. Endobronchial valves for emphysema without interlobar collateral ventilation. N Engl J Med. 2015;373:2325-35. https://doi.org/10. 1056/NEJMoa1507807.

35. Kovitz KL, French KD. Endobronchial valve placement and balloon occlusion for persistent air leak: procedure overview and new current procedural terminology codes for 2013. Chest. 2013;144(2):661-5. https:// doi.org/10.1378/chest.12-2746.

36. Travaline JM, McKenna RJ Jr, De Giacomo T, Venuta F, Hazelrigg SR, Boomer $\mathrm{M}$, et al. Treatment of persistent pulmonary air leaks using endobronchial valves. Chest. 2009;136(2):355-60. https://doi.org/10.1378/ chest.08-2389.

\section{Publisher's Note}

Springer Nature remains neutral with regard to jurisdictional claims in published maps and institutional affiliations.
Ready to submit your research? Choose BMC and benefit from:

- fast, convenient online submission

- thorough peer review by experienced researchers in your field

- rapid publication on acceptance

- support for research data, including large and complex data types

- gold Open Access which fosters wider collaboration and increased citations

- maximum visibility for your research: over $100 \mathrm{M}$ website views per year

At BMC, research is always in progress.

Learn more biomedcentral.com/submissions 